\title{
The Financial Enterprise Electronic Commerce System Design Based on WEB
}

\author{
REN xiangying ${ }^{1,}$, , WANG Yongmao ${ }^{2}$ \\ ${ }^{1}$ Qinhuangdao Institute of Technical, Qinhuangdao 066100,China \\ ${ }^{2}$ School of finance, Xinjiang University of Finance and Economics, Urumqi 830012,China \\ arenxiangying@126.com
}

\section{Keywords: Financial Enterprise; WEB; Electronic Commerce}

\begin{abstract}
With the development of world economy and the business model and change, this concept is applied to the reality of enterprise e-commerce transactions, through the network communication technology, achieve the e-commerce mode of the enterprise, the enterprise's economic business has an important value, can effectively improve the efficiency of corporate transactions, enhance the competitiveness of the enterprises, and reduce enterprise operating costs. In this paper, based on Web technology, the financial enterprise's electronic commerce system are studied. Financial enterprises of electronic commerce system will gradually realize systematization, standardization and standardization, information contents in financial enterprise e-commerce system of business management, the implementation of e-commerce platform construction, will be conducive to improve the efficiency of the office of electronic commerce and business management level.
\end{abstract}

\section{Introduction}

With the development of computer technology, Internet technology and social informatization level unceasing enhancement, electronic commerce system in the social life and economic life is more and more wide application. E-commerce has greatly changed the way business, regulate the internal process and transaction procedures, reduce the transaction of the intermediate links, reduces the enterprise the management cost, and make the business activities are no longer limited by geographical and time, convenience to customers, and close the relationship between enterprises and customers. Therefore, the electronic commerce as a trading mode more and more important role in social economic life, promising prospects $[1 \sim 2]$.With the popularity of Internet, e-commerce has become the inevitable trend of modern enterprises to carry out business activities, make full use of the data mining technology, huge amounts of information collection, e-commerce for auxiliary businesses understand user behavior, further analysis and forecast customer behavior, so as to improve the site structure, to optimize the design of the system, adjust the sales strategy, providing personalized service, find the potential market in a timely manner, enhances own competitive [3]. This paper designed a financial enterprise electronic commerce system based on Web, the system has the rich interaction, the powerful display layer logic, and the advantages of simple operation, high reliability, strong openness.

\section{System related key technologies}

With the development of computer software technology and network technology, more and more people are using B / S software architecture, software development, B / S is called a browser / server or browser / server mode, which is an improvement of C / S structure, the system only needs a server, the client to use the browser mode, people just need access to a WWW browser, you will get what they need text, video, pictures and other services, the WEB server is connected through some technology and database, a large amount of data stored in the database. In B / S structure is mainly the browser sends a request to a Web service layer and Web service layer, transaction sends a request to the back-end database, the backstage database in data processing of the requested data, 
in the specific data on the Web server to send it to the browser to display and processing [4]. B / S three layers architecture, as shown in figure 1.

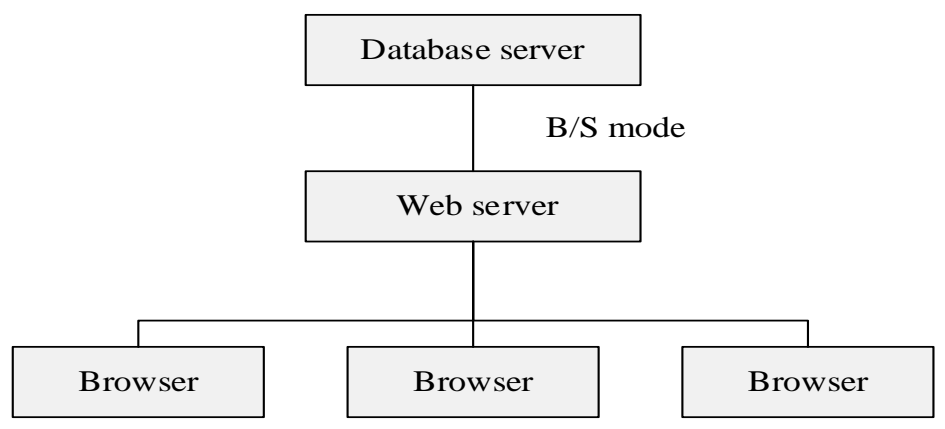

Figure 1. System structure of B/S

A lot of the rapid development of science and technology, the increase of network information, visit the web site requires users to increase speed, so the database access technology, process more worry more and more customers' expectations of the database link technology to access the ADO database access technology. The network is more and more enterprises and customers of the trust and praise from [5]. ADO. Net data access architecture is shown in figure 2.

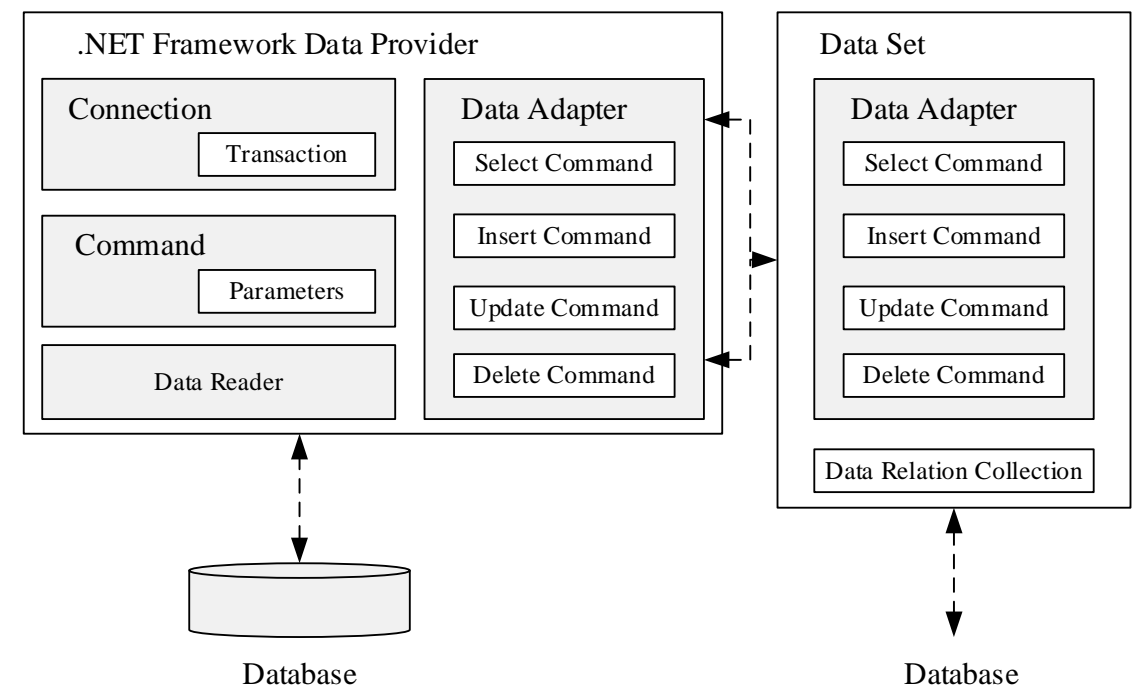

Figure 2. System structure of ADO.Net

\section{The functional needs of the financial enterprise electronic commerce system}

This paper studies the financial enterprise e-commerce business objectives, performance and functionality of the electronic commerce system demand analysis, analysis of the current financial enterprise e-commerce work, according to the survey content, such as web search, data, information disposal of data to carry on the design, use the method of network information technology, the construction of the electronic commerce system. Based on the system construction goal, in this paper, the electronic commerce system, including the background management module, including the administrator management, members, goods, warehouse, order, the administrators of operating functions, etc. Front desk function module of check all the terms of service, inquiring in shopping, modify personal information, shopping, member registration, login, etc. As shown in figure 3, the design is the business of financial enterprise electronic commerce system function modules, design the financial function of enterprise electronic commerce system structure, establishing a financial enterprise electronic commerce system and local area network structure of the corporate sector. 


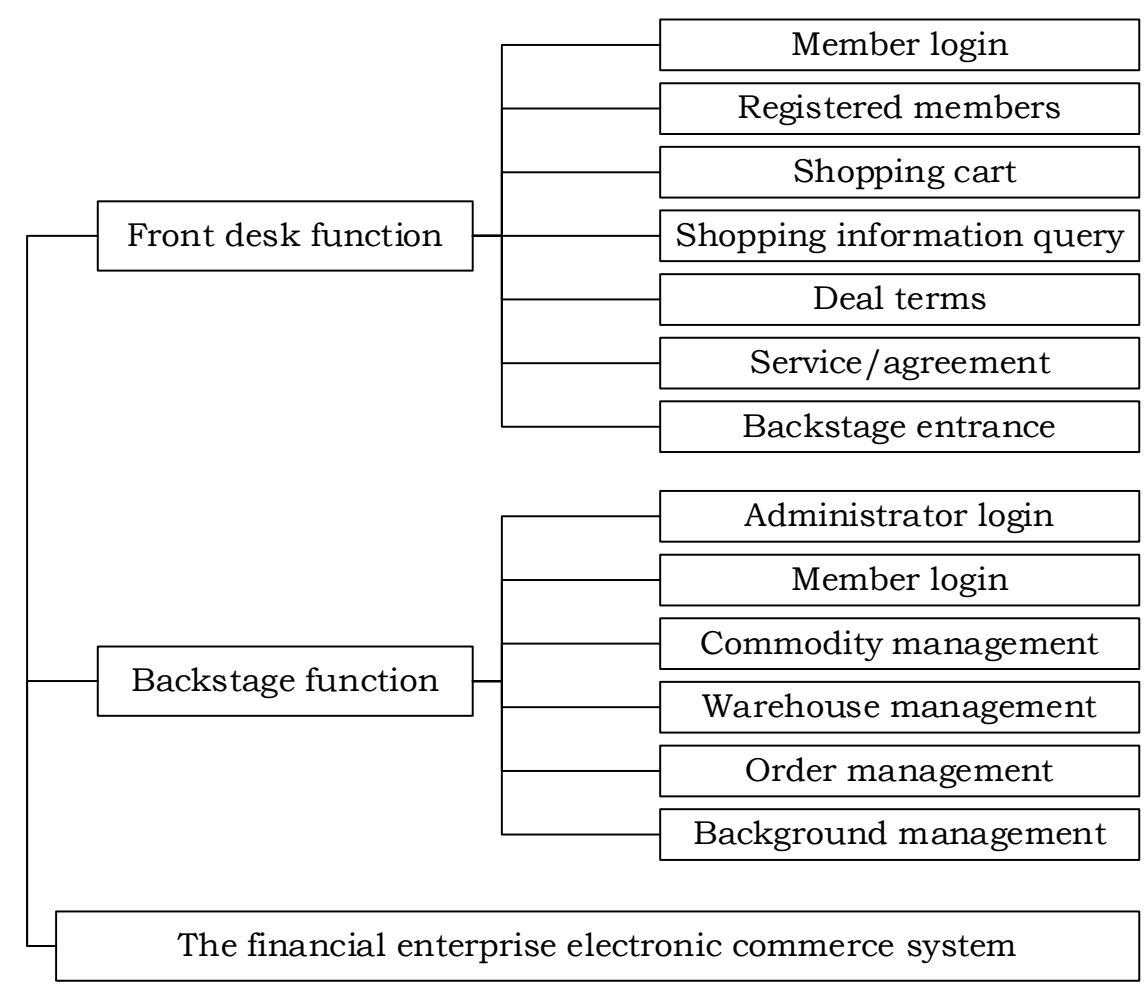

Figure 3. The functional structure of the financial enterprise electronic commerce system

Standard measure of an information system is good or bad, it is can in maximum extent, alleviate the pressure of the staff. Financial enterprise electronic commerce system of product variety, how to do a good job of scheduling management and e-commerce resources, is the foundation of e-commerce system develop smoothly, which many are complex and trivial work. This system can be full of network electronic commerce system such as data management, make the electronic commerce system management, real-time control and data of the status of the e-commerce system, easy the pressure on the staff, ensuring the electronic business smoothly.

\section{The financial enterprise electronic commerce system based on WEB architecture}

The paper involves the financial enterprise electronic commerce application system is mainly divided into two parts: financial enterprise internal management system and financial enterprises outside of the e-commerce portal. Financial enterprise internal management system through LAN and LAN server, between enterprise and customer needs through a Web server implementation, external without identification of ordinary users can access the Web server's information. Run independently, the two parts by using J2EE technology to include it in a unified platform for the technical environment and resources, can make them logically associated with each other. In the electronic commerce application system design, we adopted multi-layer architecture and especially pay attention to the specification and data exchange. The system divided into database layer, business logic layer and the Web presentation layer, the overall structure of the system is shown in figure 4. Data library and Web presentation layer technology as the core, set up the application of open and sharing platform, some of these components can run independently. The business logic layer adhered to the core business, integrating various business processes, financial management smoothly.

This paper studies the financial enterprise electronic commerce system, on the basis of sufficient demand analysis, the electronic commerce system design mainly depend on modern programming technology, ASP.NET, and use the SQL Server database design, and records management in the process of e-commerce data information, for the whole system consists of data layer, middle layer and application layer three layer structure design, with object-oriented method, under the technical framework of ASP.NET, the financial enterprise electronic commerce system was designed and developed. 


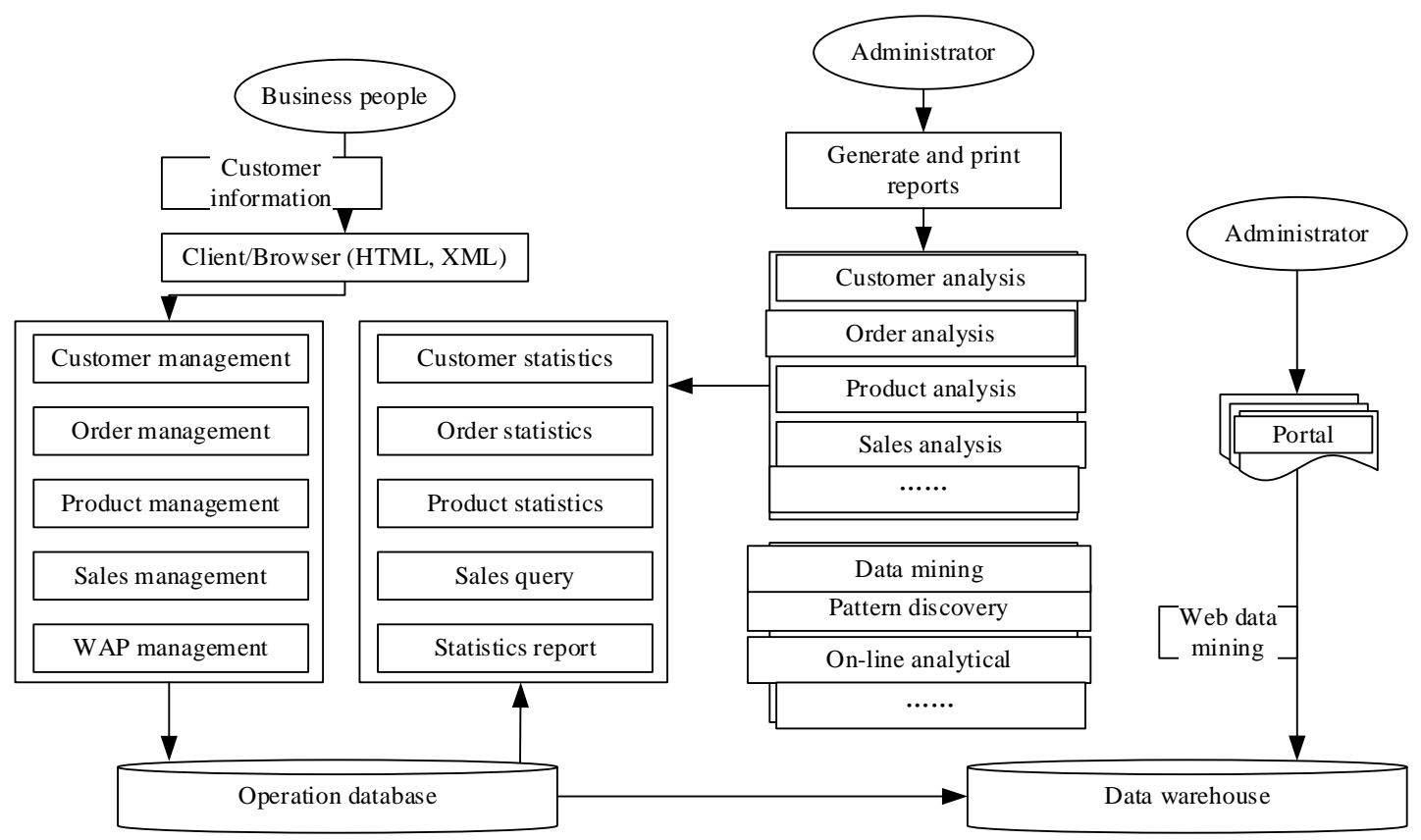

Figure 4. The structure of financial enterprise electronic commerce system based on WEB

\section{Conclusion}

With the development of world economy and the business model and change, this concept is applied to the reality of enterprise e-commerce transactions, through the network communication technology, achieve the e-commerce mode of the enterprise, the enterprise's economic business has an important value, can effectively improve the efficiency of corporate transactions, enhance the competitiveness of the enterprises, and reduce enterprise operating costs. This article is based on Web technology, in view of the system construction goal, this paper introduces the concept of e-commerce, situation, target, system architecture and technical characteristics; Analyzes the functions of the electronic commerce system requirements, environmental requirements, system use case, and analyzes the interface style, the overall performance of the system, then establishes the electronic commerce system of data flow, set up financial enterprise electronic commerce system structure, to improve office efficiency and financial enterprises of electronic commerce business management level.

\section{Acknowledgements}

Science and technology department of hebei province subject project, Project name: research problems of the rural urbanization. Item number: 12457204 - $\mathrm{d}$ - 34.

The development of social science research project in hebei province, Project name: vocational university-enterprise cooperation pattern research - based on qinhuangdao vocational and technical college in investment and financial management of the construction of the professional practice. Item number: ZJY13210.

\section{Reference}

[1] Chiou W C, Lin C C, Perng C: Information \& management, 2010, 47(5): 282-290.

[2] Sicilia M A: Europe, 2020, 2014: 17.

[3] Thomas O, vom Brocke J. A: Information Systems and e-Business Management, 2010, 8(1): 67-97.

[4] Ngai E W T, Poon J K L, Suk F F C: Information Systems Frontiers, 2009, 11(4): 405-417.

[5] Fuchs C: Handbook of research on Web, 2010, 2(3.0): 764-789. 